\title{
NOVEL METHOD OF EXTRACTION FOR RADIOCARBON MEASUREMENTS OF ATMOSPHERIC CARBON DIOXIDE
}

\author{
K L Pugsley ${ }^{1 * \text { (D) } ・ \text { T D J Knowles }}{ }^{2} \cdot \mathrm{S}_{\text {O’Doherty }}{ }^{1}$ \\ ${ }^{1}$ Atmospheric Chemistry Research Group, School of Chemistry, University of Bristol, Bristol, BS8 1TS, UK \\ ${ }^{2}$ Bristol Radiocarbon Accelerator Mass Spectrometry Facility, University of Bristol, Bristol, BS8 1UU, UK
}

\begin{abstract}
In this paper, we present the first data from an alternative extraction method for atmospheric ${ }^{14} \mathrm{CO}_{2}$ analysis, based on the direct trapping of whole air samples onto a molecular sieve zeolite (13X) trap, incorporated into a commercially available automated graphitization system. Results are presented for both inter-laboratory comparison samples and an in-house reference standard. The in-house reference was used to calculate the standard deviation of measurements $(2.0 \% 0)$. This newly developed method will facilitate faster sample processing and therefore lower cost per analysis, critical for scaling up such studies.
\end{abstract}

KEYWORDS: atmospheric ${ }^{14} \mathrm{CO}_{2}$ measurements, $\mathrm{CO}_{2}$ fossil fuel emissions, sample pretreatment, zeolite.

\section{INTRODUCTION}

Carbon dioxide $\left(\mathrm{CO}_{2}\right)$ is the most important greenhouse gas contributing to climate change (IPCC 2014). The 2015 Paris climate agreement highlights the need to reduce anthropogenic emissions by 2050 (Rogelj et al. 2016). Understanding the relative contributions of global $\mathrm{CO}_{2}$ sources is fundamental to support mitigation policies. However, $\mathrm{CO}_{2}$ source apportionment calculations currently have large uncertainties (IPCC 2014).

Radiocarbon $\left({ }^{14} \mathrm{C}\right)$, produced in the upper atmosphere by collisions of cosmic rays with nitrogen atoms, is subsequently rapidly oxidized to ${ }^{14} \mathrm{CO}_{2}$ which is distributed throughout the terrestrial, oceanic and atmospheric carbon reservoirs via the carbon cycle. There are also anthropogenic sources of ${ }^{14} \mathrm{C}$. A large amount of ${ }^{14} \mathrm{C}$ was produced and released as a result of nuclear weapons testing in the 1950 s and $60 \mathrm{~s}$ and subsequently distributed via the carbon cycle, doubling the atmospheric inventory of ${ }^{14} \mathrm{CO}_{2}$ (Nydal and Lovseth 1983; Levin et al. 1985; Manning et al. 1990). The nuclear power industry also releases ${ }^{14} \mathrm{CO}_{2}$, which offsets the depletion caused by fossil fuel combustion (Vokal and Kobal 1997; McNamara et al. 1998; Fontugne et al. 2004; Yim and Caron 2006; Magnusson 2007; Molnar et al. 2007; Dias et al. 2009; Graven and Gruber 2011; Aulagnier et al. 2012; Svetlik et al. 2012; Wang et al. 2012, 2013, 2014; Vogel et al. 2013; Metcalfe and Mills 2015; Tierney et al. 2016).

Initially, following the atomic weapons testing activities of the mid-20th century, the atmospheric levels of ${ }^{14} \mathrm{C}$ were high, with $\Delta^{14} \mathrm{C}$ values of several hundred \%o. This has now decreased to only several \%o because of the uptake of $\mathrm{CO}_{2}$ by the ocean and biosphere (Stuiver and Robinson 1974; Bozhinova et al. 2013; LaFranchi et al. 2016). Atmospheric concentration of $\mathrm{CO}_{2}$ is rising because of fossil fuel burning (Meijer et al. 2006). ${ }^{14} \mathrm{CO}_{2}$ measurements therefore provide a method of measuring fossil fuel $\mathrm{CO}_{2}$ because the absence of ${ }^{14} \mathrm{C}$ in fossil fuels results in a dilution of atmospheric ${ }^{14} \mathrm{CO}_{2}$, a phenomenon known as the Suess effect (Suess 1955), that can be quantified via atmospheric measurements. $\Delta^{14} \mathrm{C}$ determinations of atmospheric $\mathrm{CO}_{2}$ samples provide a method of quantifying fossil fuel emissions on both regional and global scales but, the scale of such efforts is limited by measurement precision, time and cost.

\footnotetext{
*Corresponding author. Email: katherine.pugsley@bristol.ac.uk.
} 
Historically, atmospheric ${ }^{14} \mathrm{CO}_{2}$ measurements were made using proportional counting methods, which required large sample sizes; these were prepared by trapping $\mathrm{CO}_{2}$ using $\mathrm{NaOH}$ over one or two weeks, then extracting the $\mathrm{CO}_{2}$ directly in the sampling device in a laboratory vacuum system by the addition of $\mathrm{H}_{2} \mathrm{SO}_{4}$, before cleaning with a charcoal column, to provide a time-integrated measurement (Levin et al. 1980, 2003). Since the development of AMS, around 1000 times less $\mathrm{CO}_{2}$ is required, making whole air flask sampling, and therefore instantaneous sampling, possible (Graven et al. 2007). Samples are collected into glass flasks (e.g. 0.7 L flasks) either instantaneously or integrated over hours (Turnbull et al. 2012). In the laboratory, $\mathrm{CO}_{2}$ is extracted from these whole air samples. Typically, cryogenic methods use dry-ice to remove water, then $\mathrm{CO}_{2}$ is isolated and purified using liquid nitrogen (Turnbull et al. 2007, 2010; Hammer et al. 2017). This $\mathrm{CO}_{2}$ is then transferred and graphitized using traditional vacuum lines (Turnbull et al. 2007). These methods require multiple extraction steps and manual intervention and are therefore, generally slow and costly. The development of automated graphitzation systems such as the Automated Graphitization Equipment (AGE) (Wacker et al. 2010c) enables increased sample throughput in the preparation of samples for ${ }^{14} \mathrm{C}$ analysis with minimal manual interventions. The continuous-flow system and zeolite $\mathrm{CO}_{2}$ trapping in the AGE3, the commercially available third generation AGE system, provides an alternative to traditional vacuum systems utilizing cryogenic trapping of $\mathrm{CO}_{2}$. The $\mathrm{CO}_{2}$ is absorbed onto a packed zeolite column and released into the reaction volume by heating the trap. We aimed to develop a simple, easily automated method for the extraction of air samples taken in simple glass flasks or Tedlar ${ }^{\circledR}$ bags.

Typically, current precision for most atmospheric ${ }^{14} \mathrm{C}$ laboratories is ca. 2-5\% (Zhao et al. 1997; Meijer et al. 2006; Turnbull et al. 2007, 2010, 2015; Hammer et al. 2017) a range which is now similar to the seasonal and spatial variability in some regions. (Graven et al. 2007) reported precisions of $1.7 \%$, expanding the usefulness of ${ }^{14} \mathrm{C}$ analysis in identifying and quantifying sources and fluxes of $\mathrm{CO}_{2}$.

The aim of the work reported in this paper was to develop and test an alternative method for $\mathrm{CO}_{2}$ extraction from air samples using an existing AGE3 system, thus providing a simple and low-cost solution for users with such equipment.

\section{METHODS}

A prototype system for the extraction of $\mathrm{CO}_{2}$ from whole air samples was designed and built in the Bristol Radiocarbon AMS laboratory (Figure 1) and is described here: Samples (in glass flasks (2L, 1.2 bar) or gas cylinders [50 L, 200 bar]) were transferred using a KNF pump (KNF N86KN.18, KNF Neuberger UK Ltd) via a phosphorus pentoxide water trap and mass flow controller (MFC, red-y smart series, GSC-B4SS-BB23, 0-600 mL/min, G1/4", Icentra, UK) to the sample inlet of the AGE3 system. The Fe catalyst was conditioned and the AGE3 system operated according to Wacker et al. (2010c). The samples were transferred to the AGE3 zeolite trap at a maximum flow rate of $180 \mathrm{~mL} / \mathrm{min}$, accurately controlled using the MFC. Atmospheric $\mathrm{CO}_{2}$ was trapped on the zeolite trap of the AGE3 system at ambient temperature before being thermally desorbed and transferred into reaction tubes, $\mathrm{CO}_{2}$ was quantified by measuring the pressure change in the reactors. A three-way valve was employed after the KNF pump to enable flushing and cleaning of the zeolite trap with Helium, to ensure the zeolite trap is under an inert Helium environment before heating. 


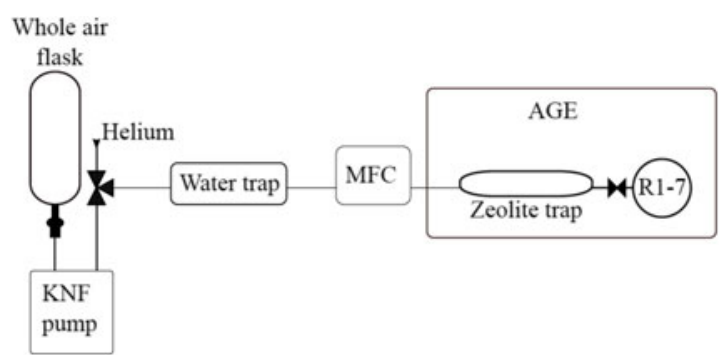

Figure 1 Schematic of the direct trapping system. The flask (NOAA design, 2L, Normag, Germany) is attached (1/2" ultratorr) to the pump (KNF N86KN.18, KNF Neuberger UK Ltd), the sample is extracted via a phosphorus pentoxide water trap via a mass flow controller (MFC, red-y smart series, GSC-B4SS-BB23, 0-600 $\mathrm{mL} / \mathrm{min}, \mathrm{G} 1 / 4$ ", Icentra, UK) directly to the zeolite trap (13X) of the AGE3 system. The AGE3 is showed simplified here (see (Wacker et al. 2010c) for full details of this system).

The graphitization reaction was carried out at $580^{\circ} \mathrm{C}$ for $120 \mathrm{~min}$, the graphite samples produced were pressed into aluminium cathodes using a pneumatic sample press.

A Luxfer cylinder was filled with dried ambient air for ${ }^{14} \mathrm{C}$ analysis $(408.2 \mathrm{ppm})$, using a SA-6 pump (200 bar, 50 L) at the School of Chemistry, University of Bristol April 29, 2016. This cylinder had a similar $\mathrm{CO}_{2}$ mole fraction to in situ ambient atmospheric samples. This in-house air reference cylinder will henceforth be referred to as the reference tank.

A number of samples $(n=38)$ from our in-house reference tank were analyzed using this new method. In addition to these 38 , seven samples extracted on the system in the initial testing phase were used. These have not been included in the subsequent analysis, all other samples extracted for $15 \mathrm{~min}$ at $180 \mathrm{~mL} \cdot \mathrm{min}^{-1}$ were included in the analysis. Radiocarbon "dead" $\mathrm{CO}_{2}$ gas $\left({ }^{14} \mathrm{CO}_{2}\right.$-free $400 \mathrm{ppm}$ in zero air, purchased from $\left.\mathrm{BOC}\right)$ was used as a processing blank and inter laboratory comparison samples $(n=11)$ were used as further quality control air standards. Normalization and AMS quality control standards, Oxalic acid II (NIST SRM 4990C) (OXII), IAEA-C7 oxalic acid and phthalic anhydride chemical blank (each at the equivalent of $500 \mu \mathrm{g} \mathrm{C}$ ), were prepared by combustion in an elemental analyzer interfaced to the AGE3.

Measurements were performed on a MICADAS AMS system (Synal et al. 2007; Wacker et al. 2010a). Data reduction was performed using BATS software (Wacker et al. 2010b). The $\mathrm{F}^{14} \mathrm{C}$ values generated were converted to $\Delta^{14} \mathrm{C}$ using Equation 1, correcting for mass dependent fractionation and age (Stuiver and Polach 1977) where $\mathrm{x}$ is the year of sample collection.

$$
\Delta^{14} C=\left(F^{14} C e^{((1950-x) / 8267)}-1\right) \times 1000
$$

Samples were analyzed until the OXII standards had achieved greater than 500,000 counts of ${ }^{14} \mathrm{C}$. 


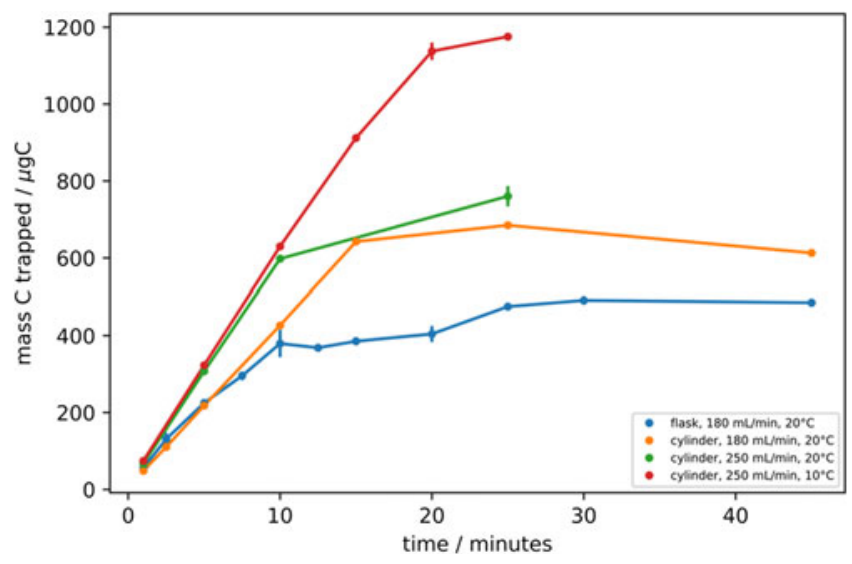

Figure 2 Time varying trapping recording the masses of $\mathrm{C}$ trapped on the zeolite, direct from flask at $180 \mathrm{~mL} \cdot \mathrm{min}^{-1}$ (blue), direct from cylinder at $180 \mathrm{~mL} \cdot \mathrm{min}^{-1}$ (orange), $250 \mathrm{~mL} \cdot \mathrm{min}^{-1}$ (green), $10^{\circ} \mathrm{C}$ (red). The uncertainty of each data point is represented as the standard deviation of repeat measurements $(n=2)$.

\section{RESULTS AND DISCUSSION}

Full characterization of the sample pretreatment was carried out. This involved: (1) investigation of the trapping efficiency under different conditions, (2) multiple analyses of air from the in-house reference tank to assess the precision of the method, and (3) comparison to other laboratories to examine the accuracy of the method.

\section{Trapping Time}

To determine the optimal length of time required to trap $\mathrm{CO}_{2}$ from a $2 \mathrm{~L}$ whole air sample in a glass flask, the trapping time was varied under different conditions. Samples were extracted directly, both from glass flasks filled from the reference tank, and directly from the reference tank itself over a range of flow rates. The zeolite trap temperatures and the measured mass of $\mathrm{CO}_{2}$ trapped were recorded (Figure 2). The AGE3 system is designed to isolate $\mathrm{CO}_{2}$ from combusted samples from the Elemental Analyzer (EA) in a stream of helium carrier gas, at a flow rate of $180 \mathrm{~mL} / \mathrm{min}$. The samples extracted from flasks with a maximum flow rate set at $180 \mathrm{~mL} / \mathrm{min}$ (this flow rate drops as the pressure of the flask is reduced). The samples extracted from the flasks (blue) demonstrated a plateau at $10-20 \mathrm{~min}$, at $400 \mu \mathrm{g} \mathrm{C}$, indicating complete isolation of the $\mathrm{CO}_{2}$. The flask trapping experiment was continued after the plateau was observed to ensure all of the sample had been trapped. A slight increase was seen from 20 to $25 \mathrm{~min}$, there are two possible reasons for this: either the flasks used in these experiments were filled to slightly higher pressures than those tested at 10-20 min therefore the plateau would have been slightly higher, or at this point, the large pressure difference between the flask (lower than ambient pressure) and the laboratory a leak into the system via the pump or flask attachment may have occurred.

To improve counting statistics and therefore improve the analytical precision, larger samples could be prepared (i.e. $1 \mathrm{mg} \mathrm{C}$ instead of $0.5 \mathrm{mg}$ ) by filling and sampling $2 \mathrm{~L}$ flasks in pairs, or filling flasks of larger volumes or at higher pressures. With larger 


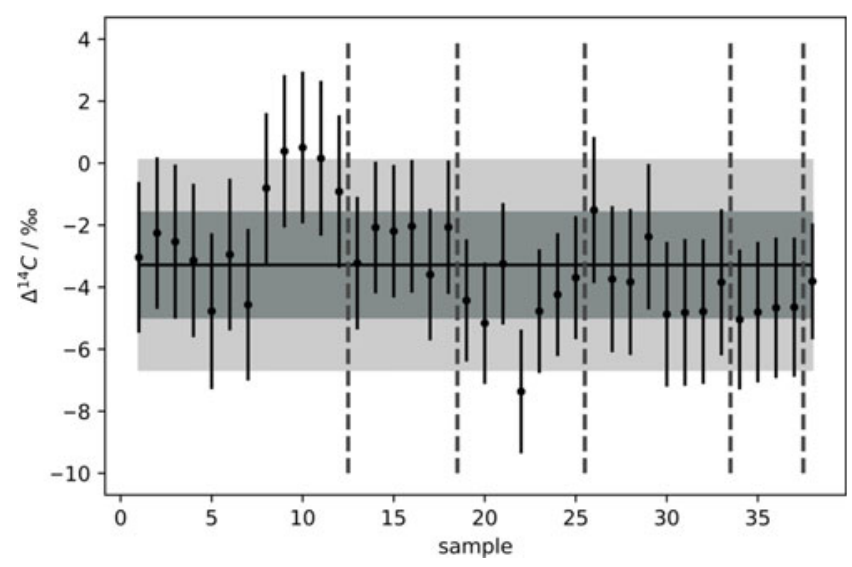

Figure $3 \quad \Delta^{14} \mathrm{C}$ values determined for the in-house reference standard extracted for $15 \mathrm{~min}$ at a max. flow rate of $180 \mathrm{~mL} \cdot \mathrm{min}^{-1}$ for 38 samples, $1 \sigma$ (grey, 1.97\% $)$ and $2 \sigma$ (pale grey, 3.94\%o). Mean represented by solid black line $\left(\Delta^{14} \mathrm{C}=-3.45 \%\right)$. All measurements were within $2 \sigma$. Vertical grey dashed lines separate measurements from different AMS magazines.

samples however, there is the potential risk of $\mathrm{CO}_{2}$ breakthrough in the zeolite trap due to its saturation. To determine the trapping capacity of the zeolite, samples from the in-house reference tank were extracted directly from the reference tank cylinder at a flow rate of $180 \mathrm{~mL} / \mathrm{min}$ (orange), ensuring that sample size was not a limiting factor. A linear increase in the quantity of $\mathrm{CO}_{2}$ trapped was observed over the initial $20 \mathrm{~min}$ of trapping, however, after this period, at $\sim 685 \mu \mathrm{g} \mathrm{C}$ a plateau was observed due to breakthrough of $\mathrm{CO}_{2}$ since the zeolite trap had reached its capacity under these conditions. The flow rate was increased to $250 \mathrm{~mL} / \mathrm{min}$ (green), and again, a linear increase was observed initially, until the same plateau level was reached at $760 \mu \mathrm{g}$, but after a shorter sampling time. The temperature of the zeolite trap was reduced to $10^{\circ} \mathrm{C}$ from an ambient trapping temperature $\left(20^{\circ} \mathrm{C}\right)$, and the capacity of the zeolite trap was observed to increase to $1200 \mu \mathrm{g}$ (red).

\section{Sample Uncertainty}

Multiple flasks filled from the reference tank were extracted for $15 \mathrm{~min}$, at $180 \mathrm{~mL} / \mathrm{min}$, with the zeolite trap at $20^{\circ} \mathrm{C}$. The extraction was performed on 38 samples. The weighted average of $\Delta^{14} \mathrm{C}$ values was determined as $-3.45 \pm 0.3 \%$. For each sample, the uncertainty of the measurement was plotted as the uncertainty $\left(\sigma_{\text {tot }}\right)$ for individual measurements (Figure 3$)$. The uncertainty includes instrument error $\left(\sigma_{\mathrm{AMS}}\right)$ that incorporates counting statistics, normalization errors and blank uncertainties. Generally, a sample scatter factor $\left(\sigma_{\mathrm{ss}}\right)$ (Equation 2), will be added using a sum-of-squares approach. This sample scatter factor is determined using chi-squared tests on repeat measurements. This accounts for any additional uncertainty resulting from sample preparation including graphitization and extraction (observed as scatter in the repeat analysis of a standard).

$$
\sigma_{t o t}^{2}=\sigma_{A M S}^{2}+\sigma_{s s}^{2}
$$


Table 1 Details regarding the AMS magazines containing samples measured as part of this study.

\begin{tabular}{lccccc}
\hline Magazine & $\begin{array}{c}\text { Number of } \\
\text { in-house } \\
\text { reference } \\
\text { samples }\end{array}$ & $\begin{array}{c}\text { Number of } \\
\text { OX II } \\
\text { standards }\end{array}$ & $\begin{array}{c}\text { Number of } \\
\text { phthalic } \\
\text { anhydride } \\
\text { blanks }\end{array}$ & $\begin{array}{c}\text { Average high } \\
\text { energy }{ }^{12} \mathrm{C} \text { ion } \\
\text { current/ } \mu \mathrm{A}\end{array}$ & $\begin{array}{c}\text { Measurement } \\
\text { time per } \\
\text { target/hr }\end{array}$ \\
\hline 20171018 & 12 & 3 & 2 & 18.4 & 1.28 \\
20171123 & 6 & 4 & 3 & 21.1 & 1.39 \\
20171213 & 7 & 3 & 2 & 24.6 & 1.17 \\
20180130 & 8 & 3 & 2 & 18.6 & 1.33 \\
20180511 & 4 & 3 & 2 & 19.9 & 1.06 \\
20180802 & 1 & 3 & 2 & 20.5 & 1.33 \\
\hline
\end{tabular}

\section{Assessment of Sample Uncertainty Contributions}

The 38 samples extracted using our new direct zeolite trapping method were measured across 6 magazines from October 2017 to August 2018 (Table 1). We performed a Pearson's chi-squared test to assess how well the observed distribution of data fits with the distribution that would be expected if the variables are independent. The right-tailed p-value $(\alpha)$ calculated for this distribution was 0.87 , suggesting that the instrument uncertainty accounts for all observed scatter. If a sample scatter value was to be added, the errors would be overestimated. It is likely that the uncertainty is currently dominated by the scatter in Oxalic Acid II standards that are prepared by combustion in the EA. The blanks from the EA method were also used in the calculation of the sample uncertainty. This is because the standard deviation of the oxalic acid was $2.5 \%$, larger than that of the reference samples which was $1.7 \%$. It is likely that the EA combustion step introduced a larger degree of sample scatter to these standards than was observed in air samples. In the future, we will investigate this further by using air standards containing $\mathrm{CO}_{2}$ from bombcombusted oxalic acids and blanks to determine a truer precision of the method.

The instrument uncertainty $\left(\sigma_{\mathrm{AMS}}\right)$ for each sample was therefore, used as the total analytical uncertainty for this study. The average uncertainty across the 38 replicate analyses was $2.0 \%$ o (on the $\Delta^{14} \mathrm{C}$ scale).

\section{Blank Analysis}

Extraction of air "blanks," consisting of zero-air mixed with radiocarbon dead $\mathrm{CO}_{2}$, using the direct zeolite trapping method produced an average value of $0.76 \pm 0.13 \mathrm{pMC}$, calculated based on measurements of blank samples independent from contamination from ambient samples $(n=15)$. The purpose of these blank analyses was to enable identical sample pretreatment of all standards. The data for these were higher than the Phthalic Anhydride blank prepared using the EA $(0.34 \pm 0.07 \mathrm{pMC})$. This is lower than observed from the isolation of our radiocarbon "dead" air standard, suggesting some contamination; the source of this is yet to be confirmed. All samples in this study contained ca. $400 \mu \mathrm{g} \mathrm{C}$, resulting in a slightly higher blank than would be observed for typical full-sized samples $(1 \mathrm{mg} \mathrm{C})$. 

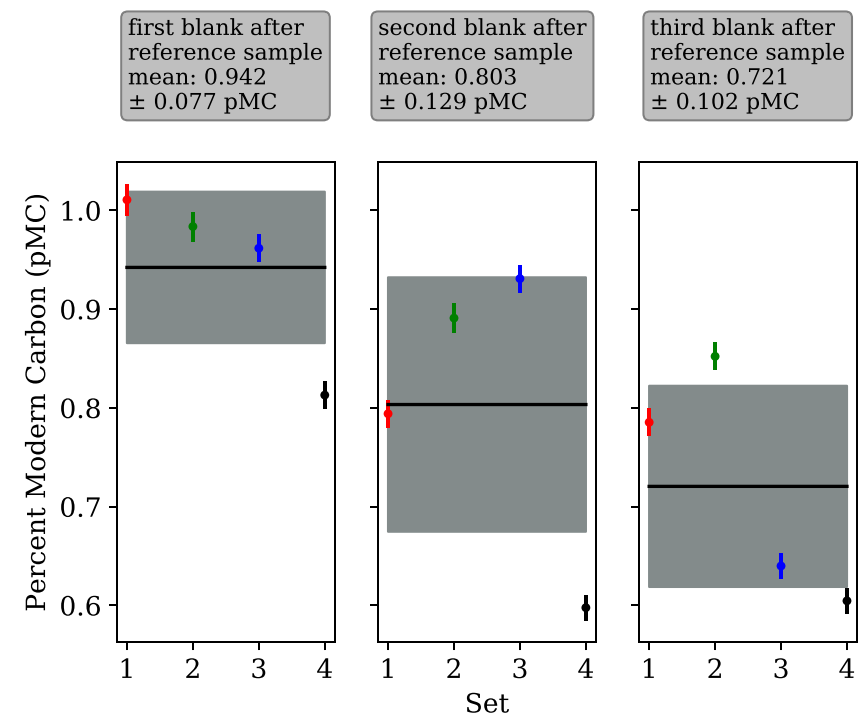

Figure 4 Cross-contamination tests. Four sets of three consecutive radiocarbon blanks isolated and graphitized after a sample of our (modern) in-house reference gas. A cross-contamination level of $1.83 \pm 1.52 \%$ o was calculated using a simple mixing model. The mean value for the first blank after the reference was $0.942 \pm 0.077 \mathrm{pMC}$, second blank was $0.803 \pm 0.129 \mathrm{pMC}$ and third blank was 0.721 $\pm 0.102 \mathrm{pMC}$.

\section{Cross Contamination}

"Modern" in-house reference samples were extracted and graphitized immediately preceding radiocarbon "dead" samples to examine the effect of cross contamination between samples. Four sequences consisting of three blanks following a sample from the in-house reference tank $\left(\Delta^{14} \mathrm{C}=-3.45 \%\right)$ were extracted, and the data are presented in Figure 4 . The first blank of each sequence was observed to be higher than the second and third.

Cross contamination can be described by a simple mixing model. A measured pMC value of the blank sample $(X, 0.942)$ depends linearly on the previous measured sample $\left(\mathrm{s}_{0}, 100.45\right)$ and the "true" pMC value of the blank $\left(\mathrm{s}_{1}, 0.76\right)$, the cross-contamination level (c), is the coefficient for the previous sample.

$$
c=\frac{X-s_{1}}{s_{0}-s_{1}}
$$

A cross-contamination level of $1.83 \pm 1.52 \%$ (or $0.183 \pm 0.152 \%$ ) was determined using Equation 3, which is significantly higher than that reported by Wacker et al. (2010c) $(0.6 \pm 0.1 \%)$. Therefore, as with the EA-AGE3 system, when analysing samples with very different levels of ${ }^{14} \mathrm{C}$, the zeolite should be pre-conditioned with a sample of similar ${ }^{14} \mathrm{C}$ content. The $\%$ cross contamination is in parts per thousand. Therefore, $0.183 \%$ of the C in one sample comes from the sample before. For example, if two samples have a difference in $\Delta^{14} \mathrm{C}$ of $10 \%$, the second sample will be shifted by $0.0183 \%$ on the $\Delta^{14} \mathrm{C}$ scale. To establish the amount of $\mathrm{C}$ from the sample transferred to the 2nd blank processed subsequently, the "effective c" value of this blank was calculated to be $0.43 \%$. The "real c," 
Table 2 Summary of our in-house reference standard extracted and measured at two different laboratories, Bristol Radiocarbon Acceletor Mass Spectrometer facility (BRAMS) and Institute of Artic and Alpine Research (INSTAAR).

\begin{tabular}{lccc}
\hline Analysis & $\begin{array}{c}\text { Number of samples } \\
\text { analyzed }\end{array}$ & $\begin{array}{c}\text { Mean } \\
\Delta{ }^{14} \mathrm{C} / \% 0\end{array}$ & $\begin{array}{c}\Delta^{14} \mathrm{C} \text { standard } \\
\text { deviation/\%o }\end{array}$ \\
\hline BRAMS, this work & 38 & -3.44 & 2.0 \\
INSTAAR & 7 & -3.80 & 1.80 \\
\hline
\end{tabular}

Table 3 Four of the samples used in the inter comparison (Hammer et al. 2017) measured during this study and the intercomparison consensus values. The chi-squared right-tailed $\mathrm{P}$ value for each sample is also reported.

\begin{tabular}{lcccc}
\hline Sample & $\begin{array}{c}\text { Number of } \\
\text { samples analyzed }\end{array}$ & $\begin{array}{c}\text { Measurement from this } \\
\text { study } \Delta^{14} \mathrm{C} / \% 0\end{array}$ & $\begin{array}{c}\text { Consensus value } \\
\Delta^{14} \mathrm{C} / \% 0\end{array}$ & $\begin{array}{c}\text { Right-tailed } \\
\text { P-values } \\
(\alpha \text { values) }\end{array}$ \\
\hline 30864 & 1 & $24.92 \pm 1.83$ & $25.2 \pm 0.7$ & 0.886 \\
30874 & 1 & $37.75 \pm 1.60$ & $40.4 \pm 0.7$ & 0.129 \\
30996 & 2 & $9.97 \pm 1.60$ & $10.9 \pm 0.7$ & 0.481 \\
31061 & 2 & $21.20 \pm 1.60$ & $22.7 \pm 0.7$ & 0.259 \\
\hline
\end{tabular}

calculated from the first blank cannot be changed regardless of the approach taken, whereas the effective $\mathrm{c}$ can change depending on the approach used (e.g. 1st +2 nd blank). This agrees with the findings of Wacker et al. (2010c) and demonstrates the efficacy of a sacrificial sample (of similar ${ }^{14} \mathrm{C}$ content to subsequent samples) between samples of very different ${ }^{14} \mathrm{C}$ content when using this system.

\section{Inter-Laboratory Comparisons}

Of great importance to atmospheric ${ }^{14} \mathrm{C}$ laboratories, and ${ }^{14} \mathrm{C}$ laboratories in general is inter laboratory comparisons to confirm that laboratories are reporting with the same accuracy and give realistic values for precision. These exercises, though of great importance for global monitoring, rarely happen (Miller et al. 2013; Hammer et al. 2017).

The results of our determination on the in-house reference standard were compared to seven flasks of the same reference tank analyzed at an independent AMS laboratory, the Institute of Artic and Alpine Research (INSTAAR), which has a long history of making atmospheric ${ }^{14} \mathrm{CO}_{2}$ measurements. These data are shown in Table 2 . The average $\Delta{ }^{14} \mathrm{C}$ values are comparable within $1 \sigma$.

Samples $(n=4)$ that previously were analyzed at the Integrated Carbon Observation System Central Radiocarbon Laboratory (ICOS-CAL), in Heidelberg, Germany were also analyzed on our new direct trapping extraction system. These samples were part of a previous inter laboratory comparison study (Hammer et al. 2017), therefore have been measured at multiple laboratories. The results of the analyses from this study were compared to the consensus values from the inter-comparison study, presented in Table 3. Samples were split into two aliquots to enable replicate measurements. Unfortunately, for samples 30864 and 30874 analysis of only one aliquot was possible. For samples 30996 and 31061 both 
aliquots were analyzed. The results presented in Table 3 are a weighted mean of these. Although all measurements were within $2 \sigma$ (and three of the four samples were within $1 \sigma$ ), all of the measurements from this study were found to be slightly lower than the consensus value. The limited size of the dataset makes interpretation of this difficult, however if there is a systematic offset it could point to a small amount of contamination with atmospheric $\mathrm{CO}_{2}$ during a leak to the system or may be because of the lower blank values. Further analysis will be required to establish this. The uncertainties reported for the consensus values are lower than any of the measurements by individual labs (including those reported here) as they were calculated based on multiple measurements at several laboratories. The uncertainties reported in this paper are similar in magnitude to the standard deviation of the measurements of the inter-comparison study at the individual laboratories, meaning this is dependent on the factors outlined above due to the combustion of the Oxalic Acid standard.

The right tailed chi-squared $\mathrm{p}$ values for each measurement shows that there is no significant difference in the measurements in this study and the consensus values. A significance level of $5 \%$ was used $(\mathrm{p}=0.05)$ and all $\mathrm{p}$ values were higher than this, meaning the null hypothesis was true and there is agreement between the measurements in this study and the consensus values within errors. This analysis was performed on a small number of samples and further comparisons with be required to ensure measurements between laboratories are comparable. The World Metrological Organisation (WMO) Guidelines state that current compatibility between laboratories is $2-4 \%$, short of the goal of $0.5 \%$ (Tans and Zellweger 2016). The comparisons made in this paper are comfortably within the compatibility reported in the WMO guidelines $(2-4 \% 0)$ as are comparable to a level of $2.7 \%$, which is the largest difference in the inter comparison experiments. Overall, our new set up has shown comparable compatibility to other AMS laboratories making atmospheric ${ }^{14} \mathrm{CO}_{2}$ measurements from other studies (Hammer et al. 2017).

\section{CONCLUSION}

We have developed and reported an alternative method for the extraction of atmospheric ${ }^{14} \mathrm{CO}_{2}$ samples. It is anticipated that this method, with the graphitization and analysis for ${ }^{14} \mathrm{C}$ using AMS, will be used for the analysis of multiple samples for quantifying fossil fuels $\mathrm{CO}_{2}$ emissions in the UK. Our initial results are promising for the future of these measurements, demonstrating agreement with other ${ }^{14} \mathrm{C}$ laboratories. We have reported a range of tests that have characterized the direct trapping system. A trapping capacity of $400 \mu \mathrm{g} \mathrm{C}$ in $15 \mathrm{~min}$ at $180 \mathrm{~mL} \cdot \mathrm{min}^{-1}$ from a $2 \mathrm{~L}$ flask has been achieved. The trapping capacity at room temperature achieved was $685 \mu \mathrm{g}$. The trapping capacity at $10^{\circ} \mathrm{C}$ was $1200 \mu \mathrm{g}$. In this work, the maximum flow rate investigated for trapping on the zeolite trap was $250 \mathrm{~mL} / \mathrm{min}$. This method has been used for pretreatment of 38 replicate samples to achieve standard deviation on long term measurements of $2.0 \%$ over 6 magazines. Assessment of the uncertainty suggests the use of an air sample containing OXII-derived $\mathrm{CO}_{2}$ rather than OXII prepared by EA-AGE3 could be advantageous as a normalization standard. Blank analysis shows that the cross-contamination level is $1.83 \pm 1.52 \%$, meaning if analyzing samples with very different levels of ${ }^{14} \mathrm{C}$, the zeolite should be pre-conditioned with a sample of similar ${ }^{14} \mathrm{C}$ content. Analysis of inter-comparison samples showed this method is comparable to two other global radiocarbon laboratories to a level of $2.7 \%$, within the WMO guidelines $(2-4 \%$ ). In the future, we will fully characterize the system to further investigate why the air blank is higher than the combustion blank, and why the 
memory effect of our line and its uncertainty are much higher than those reported in Wacker et al. (2010c). We then aim to automate the whole extraction process, integrating this to the AGE3 system to increase sample throughput and precision, vital for atmospheric ${ }^{14} \mathrm{CO}_{2}$ measurements.

\section{ACKNOWLEDGMENTS}

The authors would like to acknowledge Samuel Hammer for providing samples of his intercomparison study to test our system. This work was supported by the Natural Environment Research Council [NE/L002434/1]. We thank the two reviewers and the Radiocarbon editors for their helpful advice in improving this manuscript.

\section{REFERENCES}

Aulagnier C, Le Dizès S, Maro D, Gonze M A. 2012. Modelling the transfer of ${ }^{14} \mathrm{C}$ from the atmosphere to grass: A case study in a grass field near AREVA-NC La Hague. Journal of Environmental Radioactivity 112:52-59.

Bozhinova D, Combe M, Palstra SWL, Meijer HAJ, Krol MC, Peters W. 2013. The importance of crop growth modeling to interpret the $\Delta^{14} \mathrm{CO}_{2}$ signature of annual plants. Global Biogeochemical Cycles 27(3):792-803.

Dias CM, Stenström K, Bacelar Leão IL, da Silveira Corrêa R. ${ }^{2009} .{ }^{14} \mathrm{CO}_{2}$ dispersion around two PWR nuclear power plants in Brazil. Journal of Environmental Radioactivity 100(7): 574-580.

Fontugne M, Maro D, Baron Y, Hatte C, Herbert D, Douville E. 2004. Sources and distribution in the vicinity of La Hague Nuclear 46(2):831-839.

Graven HD, Gruber N. 2011. Continental-scale enrichment of atmospheric ${ }^{14} \mathrm{CO}_{2}$ from the nuclear power industry: Potential impact on the estimation of fossil fuel-derived $\mathrm{CO}_{2}$. Atmospheric Chemistry and Physics 11(23):12339-12349.

Graven HD, Guilderson TP, Keeling RF. 2007. Methods for high-precision ${ }^{14} \mathrm{C}$ AMS measurement of atmospheric $\mathrm{CO}_{2}$ at LLNL. Radiocarbon 49(2):349-356.

Hammer S, Friedrich R, Kromer B, Uchida M. 2017. Compatibility of atmospheric ${ }^{14} \mathrm{CO}_{2}$ measurements: Comparing the Heidelberg Low-Level Counting Facility to international accelerator mass spectrometry (AMS) laboratories. Radiocarbon 59(3):875-883.

Intergovernmental Panel on Climate Change (IPCC). 2014. Climate Change 2013 - The physical science basis: Working Group I Contribution to the Fifth Assessment Report of the Intergovernmental Panel on Climate Change. Cambridge: Cambridge University Press.

LaFranchi BW, McFarlane KJ, Miller JB, Guilderson TP. 2016. Strong regional atmospheric ${ }^{14} \mathrm{C}$ signature of respired $\mathrm{CO}_{2}$ observed from a tall tower over the midwestern United
States. Journal of Geophysical Research: Biogeosciences 121(8):2275-2295.

Levin I, Kromer B, Schmidt M, Sartorius H. 2003. A novel approach for independent budgeting of fossil fuel $\mathrm{CO}_{2}$ over Europe by ${ }^{14} \mathrm{CO}_{2}$ observations. Geophysical Research Letters 30(23): 2194-2199

Levin I, Kromer B, Schoch-Fischer H, Munnich KO. 1985. 25 years of trospheric ${ }^{14} \mathrm{C}$ observations. Radiocarbon 27(1):1-19.

Levin I, Munnich K, Weiss W. 1980. The effect of anthropogenic $\mathrm{CO}_{2}$ and $\mathrm{C}-14$ sources on the distribution of $\mathrm{C}-14$ in the atmosphere. Radiocarbon 22(2):379-391.

Magnusson Å. 2007. 14C Produced by nuclear power reactors - Generation and characterization of gaseous, liquid and solid waste [ $\mathrm{PhD}$ thesis].

Manning MR, Lowe DC, Melhuish WH, McGill RG. 1990. The use of radiocarbon measurements in atmospheric studies. Radiocarbon 32(1):37-58.

McNamara N, McCartney M, Scott EM. 1998. A review of ${ }^{14} \mathrm{C}$ waste arising from the nuclear industry in the United Kingdom. Radiocarbon 40(1):425-432.

Meijer HJ, Pertuisot MH, Plicht J. 2006. Highaccuracy ${ }^{14} \mathrm{C}$ measurements for atmospheric $\mathrm{CO}_{2}$ samples by AMS. Radiocarbon 48(3): 355-372.

Metcalfe MP, Mills RW. 2015. Radiocarbon mass balance for a Magnox nuclear power station. Annals of Nuclear Energy 75:665-671.

Miller J, Lehman SJ, Wolak C, Kondo M. 2013. Initial results of an intercomparison of AMSbased atmospheric ${ }^{14} \mathrm{CO}_{2}$ measurements. Radiocarbon 55(2):1475-1483.

Molnar M, Bujtas T, Svingor É, Futo I, Svetlik I. 2007. Monitoring of atmospheric excess ${ }^{14} \mathrm{C}$ around Paks nuclear power plant, Hungary. Radiocarbon 49(2):1031-1043.

Nydal R, Lovseth K. 1983. Bomb ${ }^{14} \mathrm{C}$ in the Atmosphere 1962-1980. Journal of Geophysical Research 88:3621-3642. 
Rogelj J, Den Elzen M, Höhne N, Meinshausen M. 2016. Paris Agreement climate proposals need a boost to keep warming well below $2{ }^{\circ} \mathrm{C}$. Nature 534(7609):631-639.

Stuiver M, Polach, H. 1977. Reporting of ${ }^{14} \mathrm{C}$ data. Radiocarbon 19(3):355-363.

Stuiver M, Robinson SW. 1974. University of Washington Geosecs North Atlantic carbon-14 results. Earth and Planetary Science Letters 23(1): 87-90.

Suess, H. 1955. Radiocarbon Concentration in Modern Wood. Science 122(3166):415-417.

Svetlik I, Fejgl M, Tomaskova L, Turek K, Michalek V. $2012 .{ }^{14} \mathrm{C}$ studies in the vicinity of the Czech NPPs. Journal of Radioanalytical and Nuclear Chemistry 291(2):689-695.

Synal HA, Stocker M, Suter M. 2007. MICADAS: A new compact radiocarbon AMS system. Nuclear Instruments and Methods in Physics Research, Section B: Beam Interactions with Materials and Atoms 259(1):7-13.

Tans P, Zellweger C. 2016. 18th WMO/IAEA meeting on carbon dioxide, other greenhouse gases and related measurement techniques (GGMT-2015). GAW Report No. 229, 18(229):13-17.

Tierney KM, Muir GKP, Cook GT, Xu S. 2016. Accumulation of Sellafield-derived radiocarbon $\left({ }^{14} \mathrm{C}\right)$ in Irish Sea and West of Scotland intertidal shells and sediments. Journal of Environmental Radioactivity 151:321-327.

Turnbull JC, Lehman SJ, Miller JB, Sparks RJ, Southon JR, Tans PP. 2007. A new high precision ${ }^{14} \mathrm{CO}_{2}$ time series for North American continental air. Journal of Geophysical Research 112(D11):D11310.

Turnbull JC, Lehman SJ, Morgan S, Wolak C. 2010. A new automated extraction system for ${ }^{14} \mathrm{C}$ measurement for atmospheric $\mathrm{CO}_{2}$. Radiocarbon 52(2):1261-1269.

Turnbull JC, Zondervan A, Kaiser J, Lehman SJ. 2015. High-precision atmospheric ${ }^{14} \mathrm{CO}_{2}$ measurement at the rafter radio-carbon laboratory. Radiocarbon 57(3):21-32.
Turnbull J, Guenther D, Karion A, Tans P. 2012. An integrated flask sample collection system for greenhouse gas measurements. Atmospheric Measurement Techniques 5(9):2321-2327.

Vogel F, Levin I, Worthy DEJ. 2013. Implications for deriving regional fossil fuel $\mathrm{CO}_{2}$ estimates from atmospheric observations in a hot spot of nuclear power plant ${ }^{14} \mathrm{CO}_{2}$ emissions. Radiocarbon 55(3-4):1556-1572.

Vokal B, Kobal I. 1997. Radiocarbon releases at the Krsko Nuclear Power Plant. Radiocarbon 39(3): 285-292.

Wacker L, Bonani G, Friedrich M, Vockenhuber C. 2010a. MICADAS: Routine and high-precision radiocarbon dating. Radiocarbon 52(2):252-262.

Wacker L, Christl M, Synal HA. 2010b. BATS: A new tool for AMS data reduction. Nuclear Instruments and Methods in Physics Research B 268(7-8):976-979.

Wacker L, Němec M, Bourquin J. 2010c. A revolutionary graphitisation system: Fully automated, compact and simple. Nuclear Instruments and Methods in Physics Research B 268(7-8):931-934.

Wang Z, Hu D, Xu H, Guo Q. 2014. ${ }^{14} \mathrm{C}$ distribution in atmospheric and aquatic environments around Qinshan Nuclear Power Plant, China. Radiocarbon 56(3):1107-1114.

Wang Z, Xiang Y, Guo Q. 2012. ${ }^{14} \mathrm{C}$ levels in tree rings located near Qinshan Nuclear Power Plant, China. Radiocarbon 54(2):195-202.

Wang Z, Xiang Y, Guo Q. 2013. Terrestrial distribution of ${ }^{14} \mathrm{C}$ in vicinity of Qinshan Nuclear Power Plant. Radiocarbon 55(1): 59-66.

Yim MS, Caron F. 2006. Life cycle and management of carbon-14 from nuclear power generation. Progress in Nuclear Energy 48(1):2-36.

Zhao CL, Tans PP, Thoning KW. 1997. A high precision manometric system for absolute calibrations of $\mathrm{CO}_{2}$ in dry air. Journal of Geophysical Research: Atmospheres 102(5): 5885-5894. 